\title{
Universiteit
}

Leiden

The Netherlands

\section{Postverbal 'can' in Cantonese (and Hakka) and Agree}

Cheng, L.L.; Sybesma, R.P.E.

\section{Citation}

Cheng, L. L., \& Sybesma, R. P. E. (2004). Postverbal 'can' in Cantonese (and Hakka) and Agree. Lingua, 114(4), 419-445.

doi:10.1016/S0024-3841(03)00067-6

Version:

License:

Downloaded from: $\quad$ https://hdl.handle.net/1887/2437
Publisher's Version

Licensed under Article 25fa Copyright Act/Law (Amendment Taverne)

Note: To cite this publication please use the final published version (if applicable). 


\title{
Postverbal 'can' in Cantonese (and Hakka) and Agree
}

\author{
Lisa L.-S. Cheng ${ }^{\mathrm{a}}$, Rint Sybesma ${ }^{\mathrm{b}}$ \\ ${ }^{a}$ ULCL/Department of Linguistics, Universiteit Leiden, PO Box 5915, 2300 RA Leiden, The Netherlands \\ ${ }^{\mathrm{b}} U L C L /$ Department of Chinese Studies, Universiteit Leiden, PO Box 5915, 2300 RA Leiden, The Netherlands
}

Accepted 7 April 2003

\begin{abstract}
This paper presents an analysis of sentences with the postverbal modal element DAK in Cantonese and Hakka. We argue that DAK is a verb, though in Cantonese and Hakka it is partly defective. It acquires different meanings depending on the position it occupies, which is either the position for modal verbs in the matrix clause or a modal position in the result denoting small clause. The analysis, if on the right track, has the consequence that there is no long distance Agree. Furthermore, it means that there is evidence for an IP-like functional projection in Chinese.
\end{abstract}

(C) 2003 Elsevier B.V. All rights reserved.

Keywords: Agree; Cantonese; Chinese; Hakka; Modal verbs

is In addition to the SLE Workshop on microvariation in the syntax of auxiliaries in Leuven, some of the research reported here was presented in Paris at the Seizièmes Journées de Linguistique d'Asie Orientale and in Sybesma's LOT Winterschool course on the superstructure of the Chinese sentence. We thank the participants in these events for comments and discussion. We further thank an anonymous reviewer and Sjef Barbiers for very helpful input. Tang Sze-Wing helped us sorting out the Cantonese data and Hsieh Feng-fan provided the Hakka data in section 5. We are grateful to both of them, as well as to several other speakers of Cantonese and Hakka who we consulted. Sybesma's research was conducted as part of his "Vernieuwingsimpuls"-project on syntactic variation in southern China, co-funded by the Dutch Organization for Scientific Research NWO, Universiteit Leiden (main sponsors) and the International Institute for Asian Studies, IIAS.

E-mail addresses: 1.1.cheng@let.leidenuniv.nl (L.L.-S. Cheng), r.p.e.sybesma@let.leidenuniv.nl (R. Sybesma). 


\section{Introduction}

This paper is about the Cantonese modal element dak. One of the reasons why this element is remarkable is that it follows the main verb, while all other modal elements in the language occur preverbally. Another reason is that it means different things in different structural positions. In accounting for the properties of dak, we take insights in Bobaljik (1995) as our point of departure and claim that the feature checking procedure of Agree is in principle followed by what we call "phonological merger", an instance of phasal spell out. However, Agree-phonological merger can only take effect when probe and goal are adjacent. In case of non-adjacency, adjacency is established by movement of the goal towards the probe. This enables us to analyse in detail and straightforwardly the distribution and meaning of $d a k$ in Cantonese, the focus of this paper. Hakka, another Sinitic language, comes in only at the end. However, the distribution of its cognate of dak, tet, offers crucial confirmation of our hypotheses regarding Cantonese. $^{1}$

\section{Cantonese dak: some facts and some issues ${ }^{2}$}

The Cantonese modal element dak appears in sentences like the following:

(1) a. keoi zaa-dak li-ga ce
3s drive-DAK this-CL car
's/he can [i.c., is permitted to] drive this car'
b. keoi lo-dak-hei li-seung syu
3s take-DAK-up this-box book
's/he can [i.c., will manage to] lift this box of books'

The two properties of $d a k$ as displayed in these sentences that are of central concern in this paper are, first, its occurrence in postverbal position, which is a-typical (all other modal elements in Cantonese precede the other verbs in the sentence) and, secondly, its meaning: as the translations indicate, although in both sentences dak can be said to mean 'can', the actual meaning in (1a) is quite different from the meaning in (1b) and both sentences are unambiguous. In (1a), dak is like a root modal, denoting permission, while in (1b) it has what is traditionally called a

1 The Sinitic languages are not unique in having a modal element in a-typical postverbal position. In many non-Sinitic languages spoken in South-East Asia we find similar phenomena, see Enfield (2002). Another recent publication on the subject is Simpson (2001). For Mandarin, as well as aspects of DAK which we cannot deal with here, see Cheng and Sybesma (2003).

2 The Cantonese described here is the variety spoken in Hong Kong. For a comprehensive overview of dak see Cheung (1972); see further Matthews and Yip (1994), Peng (1998) and Lu (1999). Our description of the negation facts does not correspond to Cheung's (1972). Our (that is, Cheng's) judgments differ from Cheung's in several respects; our informants agree with Cheng. 
"potential" interpretation. ${ }^{3}$ We borrow this term and call an interpretation "potential" if the focus is on the question whether the action denoted by the predicate can be completed successfully, that is, whether the endpoint specified can be reached. The potential reading is not the same as an ability reading, although it is not always easy to tease these two readings apart. In any case, the ability reading does not subsume the completability of an act. For (acquired) ability, Cantonese generally uses the verb sik 'know' (see (2a)), sometimes ho-ji 'can' is used, as illustrated in (2b) (both, by the way, precede the main verb).

(2) a. keoi sik zaa li-ga ce

3s know drive this-CL car

's/he can (i.c., knows how to) drive this car'

b. keoi ho-ji lo-hei li-seung syu

3s can take-up this-box book

's/he can (i.c., is able to) lift this box of books'

The sentence in (2b) is very close in meaning to (1b); if there is any difference, it lies in the focus on the completion, which is explicit in (1b), and at best implicit in (2b).

The sentences with dak in (1) are unambiguous. Sentences with dak are not always unambiguous, however. Here is an ambiguous example.

(3) keoi haang-dak-jap-heoi

3s walk-DAK-in-go

's/he can go in there'

The sentence in (3) allows for a permission and a potential interpretation. In the permission reading, the subject is allowed to enter (for example, the dentist's practice, it's his/her turn), and in the potential interpretation, the subject is, say, thin enough to manage to get inside (through a very narrow opening).

To some speakers, the sentence in (4) is also ambiguous.

(4) keoi tiu-dak

3s jump-DAK

's/he can jump'

All speakers consulted report a permission reading: 's/he is allowed to jump'; for most this is the only reading. Others report other readings as well. One such reading involves an interpretation which is close to the potential reading: 's/he managed to

\footnotetext{
3 The dak that means 'can' in the sense of permission can in some contexts also denote other root modality meaning aspects of 'can', like ability. The most general interpretation for this dak is permission, however, and for the sake of clarity, we use sentences which have this meaning only.
} 
jump up into the air'. Whatever the exact status (we return to it below), in any case, to some speakers at least, this sentence is ambiguous.

On the basis of the sentences in (1), (3) and (4), we can formulate a generalization concerning the relation between construction and interpretation. If we have a result denoting element (like hei 'up' in (1b) and jap 'in' in (3)), we for sure have a potential interpretation; if we don't have a result denoting element, we for sure have a permission reading; in cases like (1), only one reading is available. However, the conditional relation does not go both ways. The sentence in (3), with a result denoting element, allows for a permission reading as well, and (4) possibly allows for a potential reading despite the absence of a resultative element.

That there is a relation between construction and interpretation is confirmed when we look at the negative counterparts of the sentences in (1), (3) and (4). "Permissiondak" sentences have a negative counterpart which differs from that of "potential$d a k$ " sentences. In the negative counterpart of (1a), with the permission reading, the negation element $m$ 'not' precedes $\mathrm{V}+d a k$. In the potential (1b), dak is replaced by $m$ 'not'. ${ }^{4}$ For both sentences, there are no other options. This is illustrated in (5) and (6).

$$
\begin{aligned}
& \text { a. keoi m-zaa-dak li-ga ce cf. } \\
& \text { 3s NEG-drive-DAK this-CL car } \\
& \text { 's/he cannot drive this car'- permission reading only } \\
& \text { b. *keoi zaa-m-(dak) li-ga ce } \\
& \text { 3s drive-NEG-DAK this-CL car }
\end{aligned}
$$

(6)

$$
\begin{array}{lll}
\text { a. keoi lo-m-hei } & \text { li-seung syu cf. } \\
3 \mathrm{~s} & \text { take-NEG-up } & \text { this-box book } \\
\text { 's/he cannot lift this box of books'- potential reading only } \\
\text { b. *keoi } & \text { m-lo-(dak)-hei } & \text { li-seung syu } \\
\text { 3s } & \text { NEG-take-DAK-up this-box book }
\end{array}
$$

The negative counterparts of an ambiguous sentence like (3) reveals the same correlation. The sentence in (3) allows for both negative forms, but neither of these is ambiguous. The form in which $m$ 'not' precedes the verb has the permission reading, the one in which $m$ 'not' replaces dak has the potential reading. This is what we expect on the basis of our observations in (5)-(6).

(7) a. keoi m-haang-dak-jap-heoi

3s not-walk-DAK-in-go

's/he cannot go in there'- permission reading only

\footnotetext{
4 In older varieties of Cantonese, dak was optionally not replaced but directly preceded by $m$ 'not'; see Cheung (1972). Wong (1998: 117) marks V-m-dak-R explicitly as ungrammatical in modern Cantonese.
} 


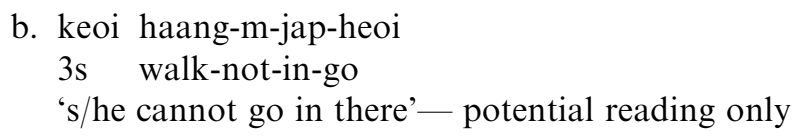

In contrast to (3), the sentence in (4) only allows for the variant in which $m$ 'not' precedes $\mathrm{V}+$ dak; other options are excluded. ${ }^{5}$

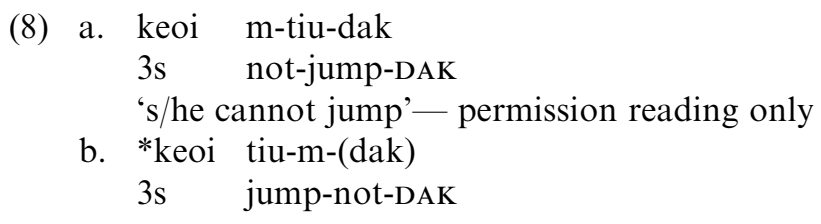

Interestingly, (8a) is not ambiguous, even to those to whom (4) is. As indicated, the only reading available is the permission reading, which is consistent with the pattern unveiled above. This pattern, to summarize, is: the permission reading correlates with $m$ 'not' preceding V-dak, the potential with $m$ replacing $d a k$, resulting in $\mathrm{V}-m$-[other material].

In sum, in Cantonese we have a modal element, dak, which occupies a position following the verb (other modals precede the verb). In principle, sentences with dak allow for two different interpretations, permission and potential, but it depends on the structural context which interpretation we get. ${ }^{6}$

5 The sentence in (8b) may be out for independent reasons. $M$ and $m$-dak never occur postverbally if not followed by other material (if $\mathrm{V}-m$-dak is ever good at all; see footnote 4).

6 Cantonese features several "other" daks, which we do not discuss in this paper. We mention them here for the sake of completeness. First, dak is used to link the verb to a postverbal descriptive modifier:

(i) keoi haang-dak hou faai

3 sg walk-DAK good fast

's/he walks very fast'

Second, it can be added to a limited number of monosyllabic verbs, meaning '-able'; this use is quite close to the potential use discussed in the present paper:

(ii) li-ga ce hou zaa-dak

this-CL car good drive-DAK

'this car is very drivable'

In addition, dak is used as what Tang (2002) calls a "focus operator" (Tang's (4)):

(iii) keoi tai dak saam-bun syu $3 \mathrm{sg}$ read DAK three-CL book 'he only read three books'

Finally, dak is used as an independent element, mostly in isolation, meaning 'okay': dak laa! /DAK SFP / 'It's okay!' or 'It's enough!'. 


\section{Some claims and assumptions}

\subsection{Two modals DAK}

To be able to account for the facts presented above, we make a number of claims which we briefly introduce in this section.

The first of these claims is that there is one modal element DAK, ${ }^{7}$ the meaning of which varies according to the structural position it occupies. We further claim that it is a verb in the sense that the structural positions it occupies may also be occupied by other modal verbs. ${ }^{8}$ Before investigating the synchronic evidence in the rest of the paper, we sketch the historical development of DAK first. From the historical literature we consulted, ${ }^{9}$ we distill the following picture. DAK started out as a full, lexical verb meaning 'get, obtain'. Several centuries B.C., it began to be used as a modal, in preverbal position (i.e., [DAK-V]), with the meaning of "objective permission" (Wang, 1980: 370). In negative sentences with permission modal DAK the negation element preceded DAK: [NEG-DAK-V].

In the first century A.D., DAK is also found as the V2 in [V1-V2] phrases, in cases in which V1 is a verb with a meaning characterizable as having the feature [+ take]: "take", "catch", "grab", etc. As the V2 following such verbs, DAK signalled success: 'grab and obtain'. Gradually losing the literal meaning of 'obtain', it started to be used with other than [+ take] verbs as well to signal the successful completion of the event. In negative sentences, the negation was placed between $\mathrm{V}$ and DAK: [V-NEG-DAK].

It is unclear (to us) whether V-DAK phrases had a potential interpretation. In any case, when DAK started to be used in between a verb and an element denoting its result, [V-DAK-R(esult)] (between the 2nd and 6th century A.D.), there is no doubt that it had the potential meaning. The negative counterpart of [V-DAK-R] was not [V-NEG-DAK-R], but [V-NEG-R] instead. It is important to note that Wang (1980: 371) suggests that the negative phrase may have existed before the positive one arose: [V-NEG-R] preceded [V-DAK-R].

Historically, then, one verb DAK 'obtain', in addition to continuing to be a full verb meaning 'obtain', got to be used as a verb expressing modality in two different ways: preverbally expressing permission, postverbally expressing potentiality. Both

\footnotetext{
7 When we generalize over $d a k$ in Cantonese and cognates of $d a k$ in other Sinitic languages, as well as when we refer to their historical predecessors, we use "DAK" in small capitals.

8 Nancarrow and Luke (1998: 92) don't classify dak as a modal auxiliary for the simple reason that it follows the verb unlike all other auxiliaries (at surface straucture). Killingley (1993: 21) treats $d a k$ as one of the aspectual particles, calling it the marker of the "abilitative". For the claim that $d a k$ is a modal verb just like all others, see Wong (1998) and the references there to unpublished work by Thomas Lee and joint work with Thomas Lee. Kwok (1971: 73) also considers dak as an auxiliary.

9 Ota (1958), Peyraube (1996), Sun (1996), Wang (1980), Yang (1989), Yang and He (1992) and Zao (1995).
} 
usages of DAK have survived to the present day, though not all varieties of Sinitic still feature both, and in several varieties, the preverbal DAK acquired other root modality meanings, like volition, obligation and ability. ${ }^{10}$

As to the synchronic status of DAK, some varieties of Sinitic still feature a fully verbal root modal DAK, preceding the other verbs, also after Spell Out. In other varieties, it is defective in one way or another. In Cantonese, for instance, dak is a bound morpheme and - we claim - it lacks the ability to check verbal features in $\mathrm{I}^{0}$ if $\mathrm{I}^{0}$ is phonologically empty. "Potential"-DAK has not survived in all Sinitic varieties; see section 5. We turn to the details of the derivation of DAK-sentences in section 4 below.

\subsection{Basic sentence structure: two positions for DAK}

The basic sentence structure we assume is given in $(9 \mathrm{~b})$. This structure incorporates the analysis of resultatives of Hoekstra (1988) (see Sybesma, 1999). The gist of this analysis is that in resultatives, the result denoting part of the sentence forms a small clause which is the complement of the verb. Although a small clause is supposed to be a basic or rudimentary kind of sentence, it is generally assumed that it consists of more structure than the structure projected by the lexical predicate alone. This is in line with the general claim in Abney (1986), that each lexical projection is dominated by at least one functional projection. In this vein, small clauses have been proposed to be AgrSPs, to give just one example (Hoekstra, 1992; Guéron and Hoekstra, 1990, 1995; see also Svenonius, 1994). We assume that in Chinese languages, the small clause always involves one F-projection, which plays a role in determining the aspect of the VP as a whole. Specifically, it indicates whether the action denoted by the VP has been realized or not. The head of this projection can, for instance, be filled by the marker that signals realization (glossed "REAL" in the examples below): le in Mandarin, zo in Cantonese (Sybesma and Vanden Wyngaerd, 1997; Sybesma, 1999, Chapter 3). ${ }^{11}$ In this paper we label it "AspP", for convenience only.

Since a small clause is, after all, a clause, it may, just like any other clause, contain a projection for a modal verb (though we claim that this projection is limited in use). As a consequence, in sentences with a resultative small clause, there are two such modal projections, "Mod1P" in the matrix clause, "Mod2P" in the embedded small clause. This is illustrated in (9a) ("ClP" stands for "ClassifierP", for our purposes equivalent to "DP"; see Cheng and Sybesma, 1999). ${ }^{12}$

\footnotetext{
${ }^{10}$ Mandarin has preverbal dei which denotes obligation. Wu (2001) reports that the Hunanese dialects have a preverbal DAK with a volition interpretation, among others. See also footnote 3 .

11 Le and zo are often referred to as "perfective markers".

12 We do not necessarily want to claim that there is such a thing as a ModP; all we want to say is that there are positions in the structure for modal verbs, not necessarily exclusively reserved for modal verbs. We use the label "ModP" for convenience.
} 
(9)

a.

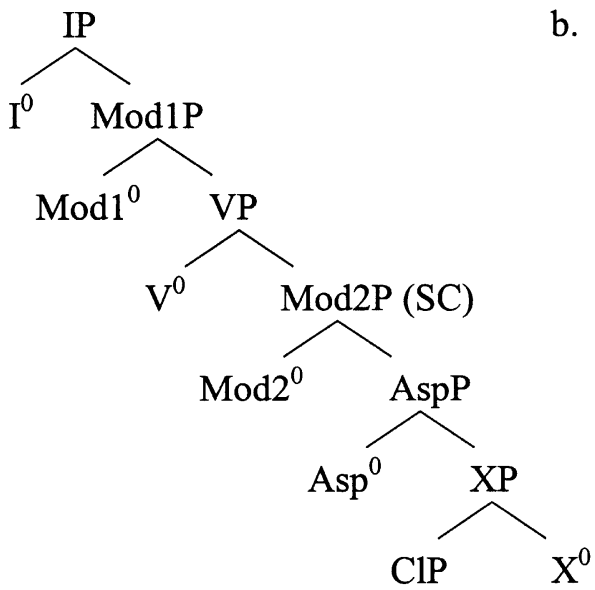

b.

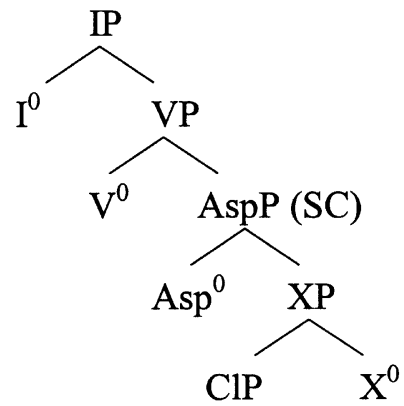

The Mod $1^{0}$ position, in the matrix clause, is the position for modal verbs generally. This is the position for preverbal DAK in languages that still have one (see footnote 10); in Cantonese, if $d a k$ is inserted in this position, it acquires its root modal meaning of permission. The $\operatorname{Mod} 2^{0}$ position, in the small clause, is limited in that it can only be occupied by DAK, which necessarily gets the potential interpretation. The necessary link between potentiality and the lower ModP is understandable. Since the small clause is a resultative small clause, embedded in the VP, what matters is whether, once the action denoted by the $\mathrm{V}$ is under way, the result will be attained or not. Within the existential bounds of the small clause in the VP this can, in terms of modality, only be a matter of potentiality as defined above, not of volitionality or permission: once we started the action, will we manage to complete it successfully or not? ${ }^{13}$

\subsection{On Agree}

To account for the data in section 2, we build on insights in Bobaljik (1995) regarding head-head relations and claim that the feature checking procedure Agree is generally followed by a process we call "phonological merger". Agree and phonological merger can however only take place when the Agreeing heads are adjacent. If they are not, movement takes place.

Among other things, Bobaljik (1995) seeks an explanation for the fact that in some cases we find verb raising while in others we don't. In cases we don't, Bobaljik argues we have "morphophonological merger", a concept borrowed from the framework of distributed morphology (see Harley and Noyer, 2003 for an overview of this framework). In simplified terms Bobaljik's explanation comes down to the

\footnotetext{
13 The top projection in the structures in (9) is labeled "IP"; we return to this below. Many details, irrelevant for the discussion at hand, are missing from the structures, the CP layer, for instance.
} 
following. First of all, movement is a last resort: if conditions are such that movement is not necessary, in other words, if features can be checked in another way, the verb does not move. The condition that has to be met is that the verb and the functional head involved in the checking relation be adjacent. This has the consequence that we always find movement when we have more than one Fhead to check features with (that is, more than two probes), since, if there are two rpobes, only one is adjacent to the goal. Thus, in a configuration as in (10b), movement is not necessary, because $\mathrm{X}^{0}$ and $\mathrm{F}^{0}$ are adjacent and there is only one F-head that features need to be checked with. In a configuration like (10a), however, movement is necessary if $\mathrm{X}^{0}$ has to check features with $\mathrm{F} 1^{0}$, since they are not adjacent.

a.

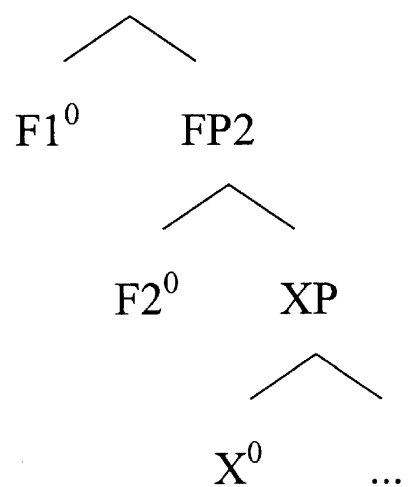

b. FP

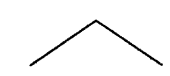

$\mathrm{F}^{0} \quad \mathrm{XP}$

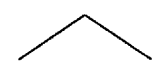

$\mathrm{X}^{0}$

Deviating from Bobaljik's system, we assume that in a configuration like (10a), the $\mathrm{X}^{0}$ does not have to raise all the way to $\mathrm{F} 1^{0}$. Raising to $\mathrm{F} 2^{0}$ will be sufficient as that will get $\mathrm{X}^{0}$ into a position adjacent to $\mathrm{F} 1^{0}$ (regardless of whether $\mathrm{X}^{0}$ has any feature checking business with $\mathrm{F} 2^{0}$ ).

On the basis of this, we claim that there is no long distance Agree. Agree can only take place when probe and goal are adjacent. If they are not adjacent, the goal will raise so as to get adjacent to the probe. ${ }^{14}$

We further claim that Agree is always followed by a process called "phonological merger". What is phonological merger? Although adjacency in itself is sufficient to ensure that the relevant features are checked, it is necessary to make sure that the effect of the checking is not lost. When checking is taken care of by Agree under adjacency, we need phonological merger to this end. Assuming a system of multiple spell out (see Chomsky, 2000, 2001; Uriagereka, 1999), we interpret phonological merger as an instance of phasal spell out.

\footnotetext{
14 We don't have space to discuss the wider consequences of this claim here.
} 
Chomsky $(2000,2001)$ states that, since the distinction between interpretable and uninterpretable features is lost after Agree has taken place, and spell out is supposed to remove the uninterpretable features from the syntactic object, "[t]o operate without reconstructing the derivation, Spell-Out must therefore apply shortly after the uninterpretable features have been assigned values at this point", that is directly after the checking operation Agree has taken place (Chomsky, 2001: 5). In the case at hand, then, as soon as the right configurational relation of adjacency has been established and Agree has taken place, spell out must take effect. (The consequence of our interpretation of what happens is that we must assume that in certain cases spell out concerns phases including the head.)

For our purposes it is important to note that once a phase has been spelled out, the constituting parts are no longer syntactically accessible. In the words of Uriagereka (1999: 256-257): "[T]he phrase marker that has undergone Spell-Out is like a giant lexical compound, whose syntactic terms are obviously interpretable but are not accessible to movement, ellipsis, and so forth." Also, since this "giant lexical compound" is not a syntactic head, it can also not be involved in head movement. It can, however, be the goal in an Agree relation.

Let's now return to the facts in Section 2 and see how they fall out under this theory of Agree.

\section{The derivations}

\subsection{The derivation of (1a) and (1b) and why they are not ambiguous}

\subsubsection{Sentence (1a)}

The case constituted by (1a), repeated here, is quite straightforward. Since we have no result denoting small clause, we only have a ModP in the matrix clause, in which position dak has the permission reading. This is why (1a) is unambiguous. As to the derivation, Mod $1^{0}$ is occupied by dak and whereas other modal verbs are able to check the verbal features in $\mathrm{I}^{0}$ (which is empty), dak cannot do so. As a consequence, the verb zaa 'drive' raises to the position occupied by dak, thus forming a complex head zaa-dak 'drive-DAK' and moving itself into a position adjacent to $\mathrm{I}^{0}$, close enough for Agree to take effect. The derivation is indicated in (11).

(1) a. keoi zaa-dak li-ga ce

3s drive-DAK this-CL car

's/he can drive this car'- permission reading only

$\begin{array}{llllll} & & \text { Mod1 } & \text { V } & \text { Obj } & \\ \text { a. } & \text { keoi } & \text { dak } & \text { zaa } & \text { li-ga } & \text { ce } \\ & \text { 3s } & \text { DAK } & \text { drive } & \text { this-CL } & \text { car }\end{array}$




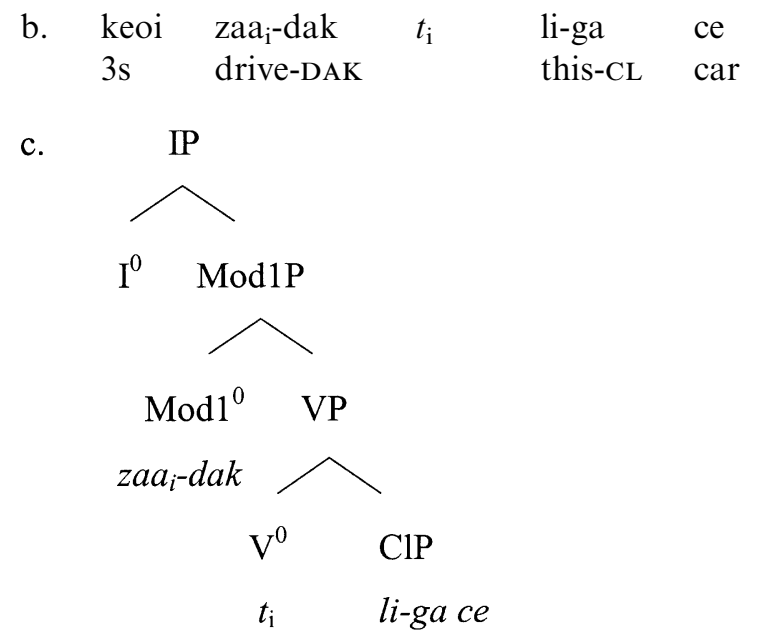

4.1.2. Sentence (1b)

4.1.2.1. The derivation of "simple" resultatives. With respect to (1b) (repeated here) the situation is more involved.

(1) b. keoi lo-dak-hei li-seung syu 3s take-DAK-up this-box book 's/he can lift this box of books'- potential reading only

First, we have to make clear what the checking requirements are and which elements are involved. Secondly, we have to explain why (1b) is unambiguous: since the sentence contains a result denoting clause, it may in principle contain both a Mod1P and a Mod2P.

To be able to address the first issue, we have to look at the derivation of a resultative sentence without $d a k$. An example of what we call a "simple" resultative (there is another one, dubbed the "plus-type" here; see section 4.1.2.4) is given in (12a), the basic structure in (12b) and (12c).
a. keoi lo-hei- zo li-seung 3s take-up-REAL this-box 's/he lifted this box of books'
b. keoi lo 3s take [sC ZO $\begin{array}{lllll}\text { REAL } & \text { [XP } & \begin{array}{l}\text { li-seung } \\ \text { this-box }\end{array} & \text { byu } & \text { heok } \\ & & \text { up }\end{array}$ 
c.

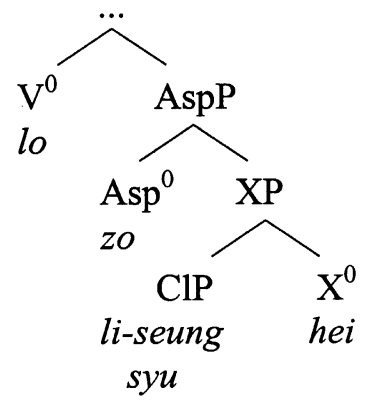

d.

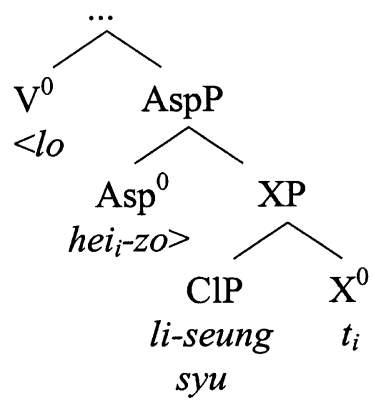

We assume that, generally, in order to facilitate temporal interpretation among other things, all verbal and predicative elements in a sentence must be in a chain relationship ("T(ense)-chain"; Guéron and Hoekstra, 1989, 1995). ${ }^{15}$ This includes predicative elements in small clauses. Presumably, for fully verbal elements, being in the right configuration is enough, while for non-fully verbal elements (like adjectives and $d a k$ ) explicit checking in the usual ways is necessary.

In (12), hei 'up', the predicate head of the resultative small clause (labeled " $\mathrm{R}$ " and " $\mathrm{X}^{0}$ " interchangebly), needs to check features with both $\mathrm{V}^{0}$ and $\mathrm{Asp}^{0}$ (different ones). Since it is not adjacent to the former, it moves to the latter, which is occupied by the aspectual morpheme $z o$. There, it checks features with $\mathrm{Asp}^{0}$ as well as with $\mathrm{V}^{0}$ to which it is now adjacent. Subsequently, phonological merger takes place of the material in $\mathrm{V}^{0}$ and $\mathrm{Asp}^{0}$, yielding <lo-hei-zo> 'take-up-REAL: lifted' (here and elsewhere, phonological merger is indicated with angled brackets). ${ }^{16}$

The resulting word order in simple resultatives like (12) is: $\mathrm{V}-\mathrm{R}-z o-\mathrm{O}$ (bject). It must be noted that if there is no $z o, \mathrm{R}$ (the resultative predicate head $\mathrm{X}^{0}$ ) still raises, leading to the order $\mathrm{V}-\mathrm{R}-\mathrm{O}$. The aspectual AspP is always there, even if its head is phonologically empty, and there is always something aspectual to check. That this is the case may be deduced from the sentence in (13) (hei 'up' being the $\left.\mathrm{X}^{0}\right)$.

(13) keoi seung lo-hei li-seung syu

3s want take-up this-box book

's/he wants to lift this box of books'

\footnotetext{
15 Or whatever other reason there is why small clause predicates cannot stay put; see Koopman and Szabolsci (2000) and refernces cited there.

16 If phonological merger is an instance of phasal spell out, as we think it is, the whole result denoting clause is involved, of course, including the small clause subject (li-seung syu 'that box of books' in (12)). For the sake of focusing, we only bracket the verbal elements.
} 
4.1.2.2. The derivation of ( $1 \mathrm{~b})$. The derivation of (1b) is presented in (14). Dak, which occupies $\operatorname{Mod} 2^{0}$, has to check features with $\mathrm{V}^{0}$. Since it is adjacent to it, it can stay put. $\mathrm{X}^{0}$, the predicative head of the resultative small clause, has to check features with $\mathrm{Asp}^{0}$ and dak, with the latter for reasons of T-chain-formation, as mentioned above. It moves to the former, in which position it can check features with both. The next thing that happens is that phonological merger takes place, involving $\mathrm{V}^{0}$, dak and the $\mathrm{X}^{0}$ in $\mathrm{Asp}^{0}$. Presumably, things happen in a bottom-up fashion, but the result is the same.

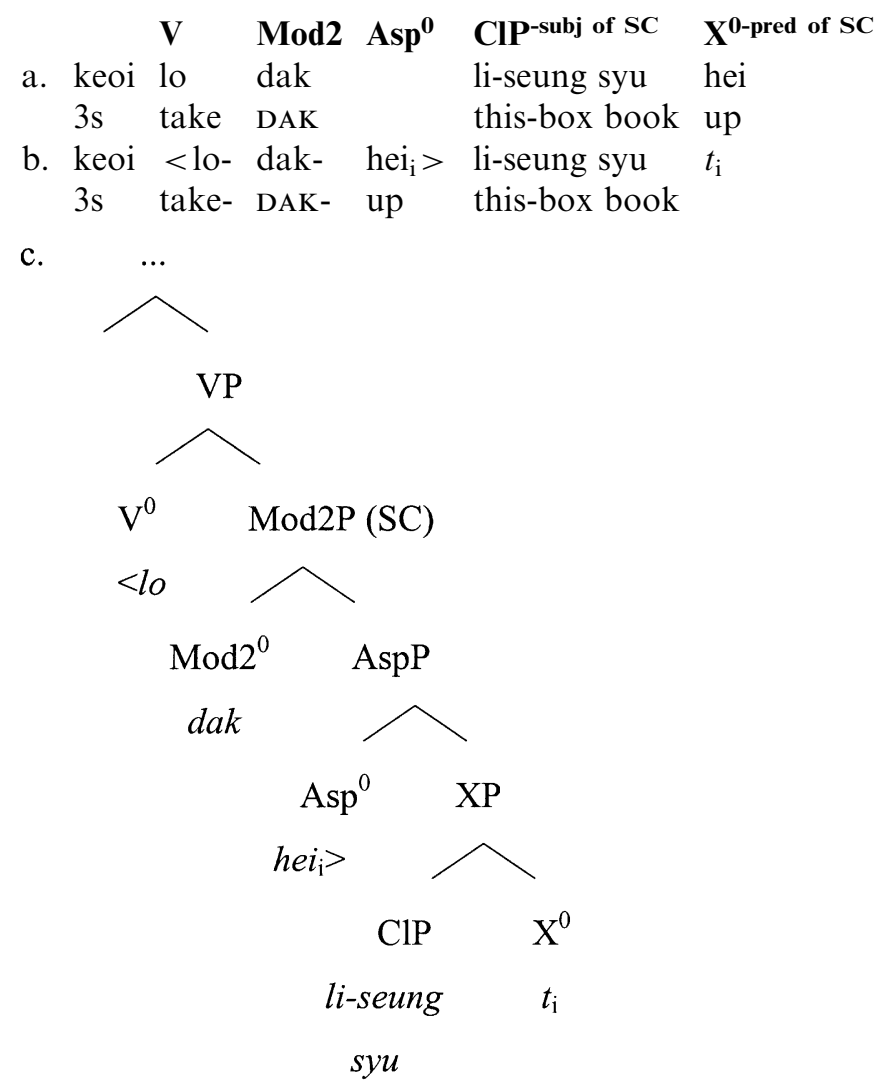

4.1.2.3. Why (1b) is not ambiguous. The second question to be addressed in the context of $(1 b)$ is why it is not ambiguous. Since we have a result denoting small clause, we potentially have both ModPs in (9a). In other words, the question why (1b) is not ambiguous comes down to asking why (15), with dak in Mod $1^{0}$ instead of $\operatorname{Mod} 2^{0}$, is not a possible underlying structure for (1b). 
(15)

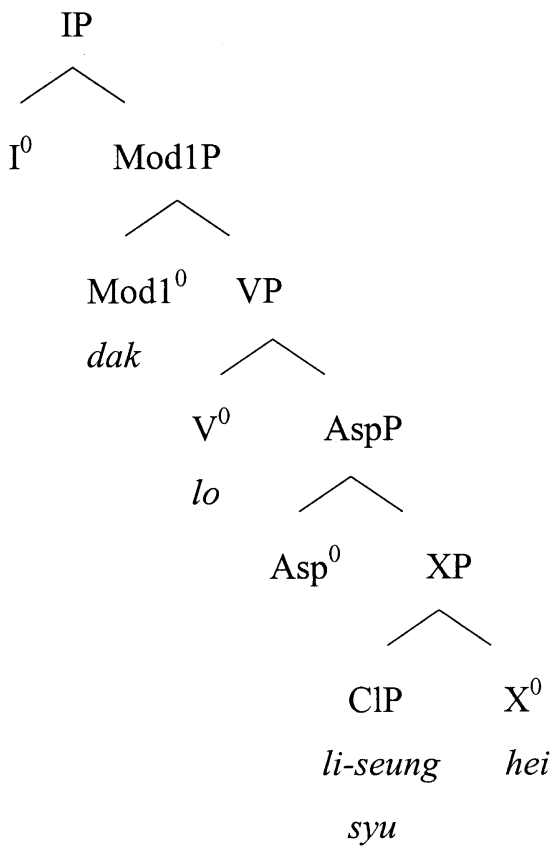

In (15), we have $d a k$ in $\operatorname{Mod} 1^{0}$ and we have a verb, which is complemented by a small clause, AspP. The predicate of the small clause is hei 'up' and the subject it predicates of is li-seung syu 'this box of books'. In the by now familiar way, hei 'up' will move to $\mathrm{Asp}^{0}$ and will subsequently undergo phonological merger with $\mathrm{V}^{0}$. This is where the problem lies. As noted above, once phonological merger has taken place, the verb ( $l o$ 'take' in our example here) is "stuck" as part of a larger whole and cannot be excorporated to move to dak in Mod1 $1^{0}$. The larger whole is also unmovable. And since dak cannot check the features in $\mathrm{I}^{0}$ by itself, the derivation crashes. This is why (1b) is unambiguous and can only have (14c), with potential$d a k$ in $\operatorname{Mod} 2^{0}$, as the underlying structure.

4.1.2.4. Evidence from "plus-type" resultatives. In section 4.1.2.1 we have looked at the derivation of what we called a "simple" resultative sentence. For the purpose of this paper we distinguish one more type, the "plus" variant. In a simple resultative, the small clause has a simple predicate, an $\mathrm{X}^{0}$. The plus variants involve a small clause which contains this $\mathrm{X}^{0}$ plus an element meaning 'come' or 'go' (lei and heoi respectively). Examples are given in (16).

$\begin{array}{lll}\text { (16) a. keoi lo-zo di-cin } & \text { ceot-lei } \\ \text { 3s take-REAL CL-money } & \text { out-come } \\ \text { 's/he took the money out' } & \end{array}$ 

b. keoi lo-zo li-seung syu hei-lei
3s take-REAL this-box book up-come
's/he lifted this box of books'
$\begin{array}{llll}\text { c. } & \text { keoi seung lo } & \text { li-seung syu hei-lei } \\ 3 \mathrm{~s} & \text { want } & \text { take } & \text { this-box book up-come }\end{array}$
compare to (12)
's/he wants to lift this box of books'
compare to (13)

The derivation of the plus variants differs in one important respect from their simple counterparts. Unlike the predicate in (12), the predicate-plus-lei does not raise to $\mathrm{Asp}^{0}$, as shown in (17). We do not know what the structural relationship between $\mathrm{R}$ and lei/heoi is; the reason why $\mathrm{R}$ does not raise must be related to lei/heoi, though, as, first of all, they are fully verbal elements and secondly have been argued to play an aspectual role ( $\mathrm{Li}, 1996)$, comparable to $\mathrm{Asp}^{0}$. Whatever features $\mathrm{R}$ needs to check with $\mathrm{Asp}^{0}$ in simple cases are presumably checked with lei 'come' or heoi 'go' in the plus variants.

a.

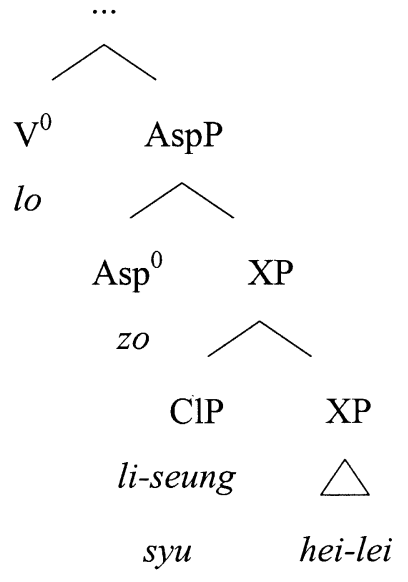

b.
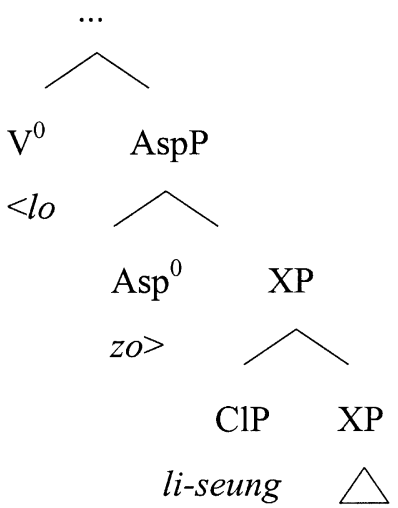

syu hei-lei

As to the rest of the derivation, despite the fact that nothing raises to Asp ${ }^{0}$, phonological merger between $\mathrm{V}^{0}$ and the material already present in $\mathrm{Asp}^{0}$ still takes place, as indicated in (17b) by the angled brackets. The resulting word order in plus type resultatives is $\mathrm{V}-z o-\mathrm{O}-\mathrm{R}-l e i / h e o i$.

What is crucial to us is that when $\mathrm{Asp}^{0}$ is phonologically empty and remains so because nothing raises to that position, $\mathrm{V}^{0}$ does not phonologically merge with anything - we are dealing with phonological merger after all. An example of a sentence with no Asp-related material was given in (16c).

The reason why this is crucial is that we ruled (15) out as a possible underlying structure for $(1 \mathrm{~b})$ on the ground that the derivation will crash as a result of the verb 
being "stuck" after having phonologically merged with material in the small clause. This was the explanation for why (1b) is not ambiguous. If this is right, we predict that dak-sentences formed on the basis of resultatives of the plus-variant are ambiguous, since in those cases the verb is "free".

This prediction is borne out. The sentence in (18a) is a dak-sentence based on a plus-type resultative and it is ambiguous between a potential and a permission reading; it has either (18b) or (18c) as its underlying structure.

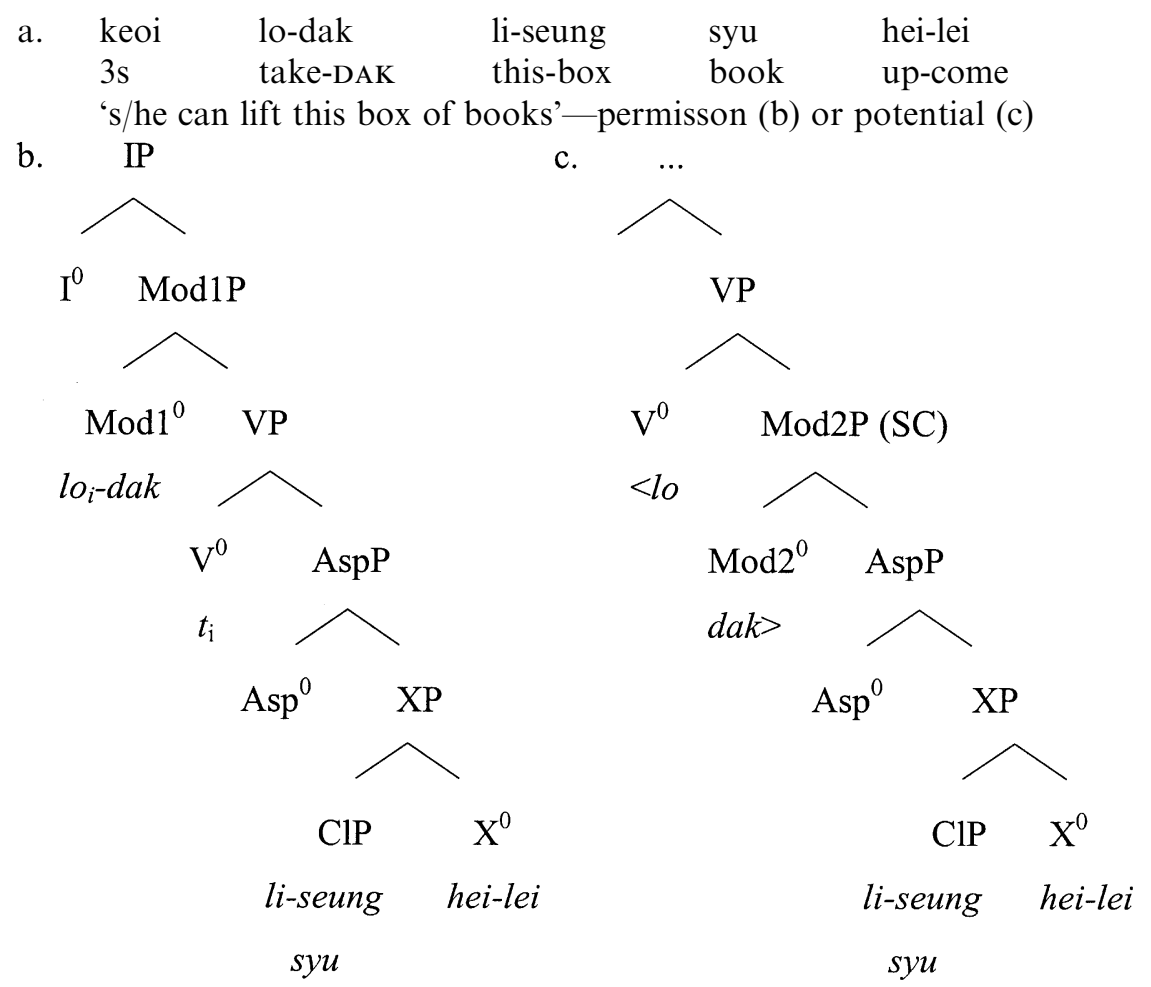

In the permission reading (see (18b)), dak is in $\mathrm{Mod}^{0}$. Since $\mathrm{X}^{0}$ hei 'up' does not raise to $\mathrm{Asp}^{0}$ as a result of its association with $l e i$ 'come' and, as a consequence, $\mathrm{Asp}^{0}$ remains phonologically empty, $\mathrm{V}^{0}$ lo 'take' is not phonologically merging with anything. As a result, it is free to raise to $\operatorname{Mod}^{0}$ to get adjacent to $\mathrm{I}^{0}$ saving the structure from crashing. The derivation of the sentence with the permission reading is essentially the same as that of (1a).

The derivation of the sentence with the potential reading (as in (18b)) is similar to the derivation of (1b). Now, dak occupies Mod $2^{0}$ and phonologically merges with the verb. The fact that the small clause predicate hei 'up' does not move to $\mathrm{Asp}^{0}$ is irrelevant here. 
In sum, our explanation for the unambiguity of (1b) (the verb is stuck as a result of the phonological merger) is confirmed by the ambiguity of (18a) in which the verb is free.

\subsection{The derivation of (3) and (4) and why they are ambiguous}

\subsubsection{Sentence (3)}

Neither the derivation of (3), repeated here, nor the question why it is ambiguous is a problem for us. Indeed, in view of the presence of the element heoi 'go', the ambiguity is expected.

(3) keoi haang-dak-jap-heoi

3s walk-DAK-in-go

's/he can go in there'-both permission (19a) and potential (19b) possible

In all relevant respects, the derivation of the structures underlying the two sentences (one permission sentence, one potential sentence) is the same as was indicated for (18a) in (18b) and (18c). For the sake of completeness, here are the structures corresponding directly to (3) ((19a): permission reading; (19b): potential), given here without further explanation.

(19)

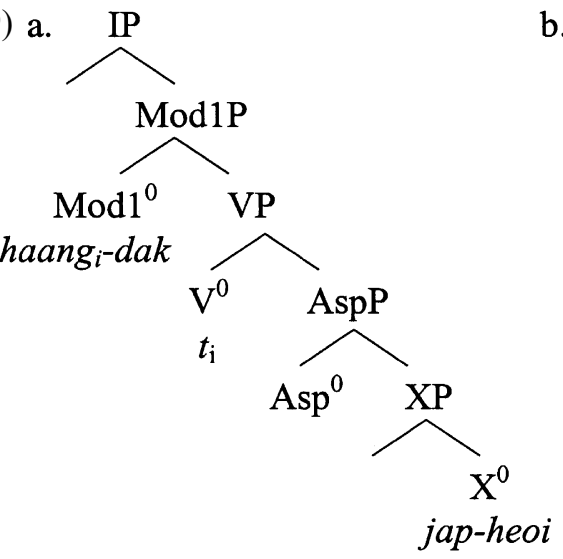

b.

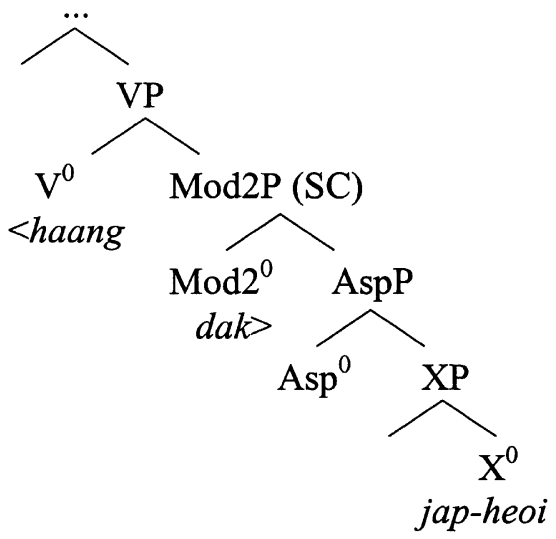

We can test our hypothesis regarding the crucial role played by the verb being stuck in the small clause or not backwards, by looking at haang 'walk' in the context of a simple small clause, without lei 'come' or heoi 'go', and see whether such situation combined with dak will lead to an unambiguous potential reading; this would be the prediction in view of the claim that in the absence of lei 'come' or heoi 'go' the predicate of the small clause will immobilize the verb. The prediction is borne out. The expression haang-hoi 'walk-away' is often used with dak or $m$, the latter indicating that one is so busy and has so much work to do that one won't possibly manage to get away. 
(20) a. ngo haang-dak-hoi

I walk-DAK-away

'I can leave/get away'

b. ngo haang-m-hoi

I walk-NEG-away

'I can't leave/get away'

The interpretations given are the only ones possible; a permission reading is inconceivable.

\subsubsection{Sentence (4)}

The status of (4) (repeated here) was unclear: although most speakers only have the permission reading, some seem to have a reading very close to what we defined as the potential reading; to those speakers, the sentence has a reading like 'manage to jump up into the air'.

(4) keoi tiu-dak

3s jump-DAK

's/he can jump'

In view of the absence of a result denoting small clause, we expect to find the permission reading, indeed, we expect it to be the only reading; the potential should not come up at all. The structure would correspond closely to that of (1a) in (11c); see (21).

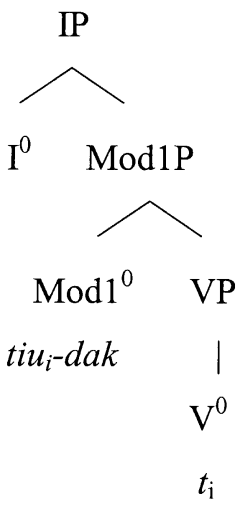

The only explanation for the fact that to some speakers the sentence in (4) has a potential interpretation is that, despite everything, it does have a result denoting small clause; it is there, but the $\mathrm{X}^{0}$ is empty. The structure would be as indicated in (22a) and is very similar to (14) given for (1b), with the $\mathrm{X}^{0}$ being empty; see also the intransitive structures in (19). 
(22) a.

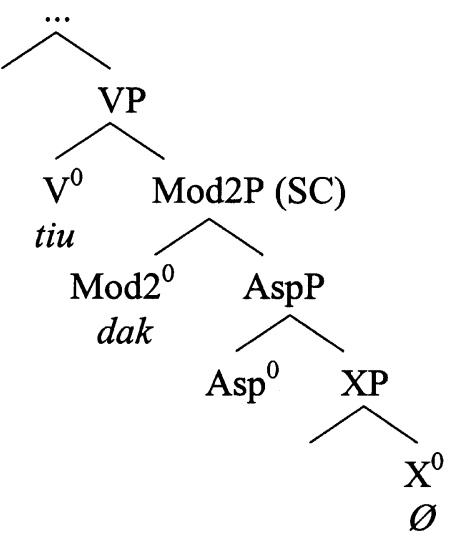

b.

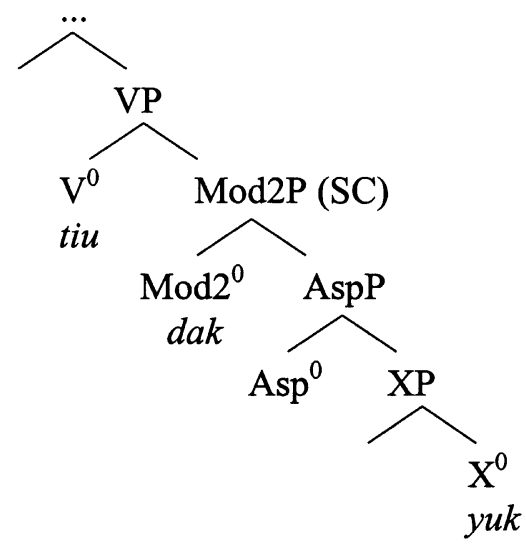

The idea of a covert small clause predicate is not new (cf. Hoekstra, class lectures 1990s; Sybesma and Vanden Wyngaerd, 1997). Covert small clause predicates are thought to express the typical result of an activity. In the case of "jump", this would be something like "up". In the case at hand, the postulation is motivated by two things. First, tiu 'jump' is an activity verb and activity verbs can always be combined with a result denoting small clause expressing, or making explicit, the end point of the activity. Secondly, the empty predicate can be made overt. Probably for lexical reasons, hei 'up' cannot be used and the other element meaning 'up', seung, can only be used together with lei 'come' or heoi 'go', but Cantonese has the element $y u k$ denoting 'move - in any direction', which we can use to replace the empty predicate in (4) in the potential reading and (22a). The sentence is given in (23), the accompanying structure has already been given in (22b). Note that, as expected, the sentence in (23) is not ambiguous.

$$
\begin{aligned}
& \text { keoi tiu-dak-yuk } \\
& \text { 3s jump-DAK-move } \\
& \text { 's/he can jump'-potential only }
\end{aligned}
$$

The following sentence, however, is; this is also expected: it runs parallel to (3), and the structures in (19).

\section{(24) keoi tiu-dak-seung-lei \\ 3s jump-DAK-up-come \\ 's/he can jump up'-potential and permission possible}

Although this explanation of the ambiguity of (4) is feasible, it is hard to verify. To verify it we would have to take other activity verbs like tiu 'jump' (i.e., unergative intransitives), combine them with $d a k$ and see what interpretation we get. The problem is that Chinese languages have an extremely small number of 
unergative intransitive activity verbs, if they exist at all (Cheng and Sybesma, 1998). ${ }^{17}$ In Cantonese, aside from tiu 'jump', the only other examples seem to be siu 'laugh' and haam 'cry'. It is, however, hard to imagine what the typical end point of these activities would be. As a consequence, the following sentences seem to allow for a permission reading only. This is not necessarily a grammatical matter. ${ }^{18}$

$$
\begin{aligned}
& \text { a. keoi siu-dak la } \\
& \text { 3s laugh-DAK SFP } \\
& \text { 's/he can laugh again now' } \\
& \text { b. keoi haam-dak la } \\
& \text { 3s cry-DAK SFP } \\
& \text { 's/he can cry again now' }
\end{aligned}
$$

\subsection{The negation facts}

In section 2 we found a correlation between the meaning of a sentence with dak and the negative counterpart of the sentence: the negative counterpart of permission sentences with $d a k$ have $m$ 'not' in front of $\mathrm{V}$-dak, while negative potential sentences replace dak with $m$. Given the discussion in subsequent sections we can phrase this correlation by stating that $d a k$ in $\operatorname{Mod}^{0}$ and $d a k$ in $\operatorname{Mod} 2^{0}$ are not negated by the same element in the same structural position. Before we look at the two cases separately, we say a few general words on negation in Chinese.

Negation is a much discussed topic in Chinese linguistics. ${ }^{19}$ Aside from discussion generated by the existence of two negative elements, one for unbounded predicates and modals ( $b u$ in Mandarin, $m$ in Cantonese) and one for bounded predicates ( $m e i$ or meiyou 'not have' in Mandarin, mou 'not have' in Cantonese) there is discussion on the grammatical status of these elements. While Mandarin meiyou and Cantonese mou are generally acknowledged to be negative verbs, there is more discussion on the other elements, Mandarin $b u$ and Cantonese $m$. The general consensus in the theoretically inclined literature is that these negation elements are clitic-like or affixal elements. Disagreement exists on the matter of what they cliticize to or affix onto. Yip (1988: 455) argues explicitly that Cantonese $m$ 'not' 'directly pr[e]cedes [+ V] elements only" and Huang (1988: 284) argues for his "Principle P", stating that bu 'not' in Mandarin "forms an immediate construction with the first $\mathrm{V}^{0}$ element

\footnotetext{
17 Cantonese (and Mandarin) counterparts of most unergative intransitives in English involve a nonreferential (dummy) object. See Cheng and Sybesma (1998) for an account. There we give Mandarin examples, here are some Cantonese ones: stroll: saan-bou 'disperse step'; walk: haang-lou 'walk-street'; move: bun-uk 'move house'; swim: jau-seoi 'travel water'.

18 An alternative explanation for the ambiguity of (4) is that we are not dealing with a potential interpretation but with an ability interpretation. This reading would stem from 'ability'-dak in Mod $1^{0}-\operatorname{see}$ footnote 3 . In that case, the sentence never involves a resultative structure.

19 See for instance: Yip (1988), Huang (1988) and Ernst (1995), and references cited there.
} 
following it". Ernst $(1995,667)$, in contrast, defends the claim that Mandarin bu 'not' "is proclitic on the following word" - emphasis ours: not just a verbal head, but any word will do. In addition, Huang (1988: 286) assumes that $b u$ is "base-generated as a bound form in an INFL node", which under certain conditions may lead to verb raising. For Ernst (1995: 703), the negation element in Mandarin is in the "Spec of AspP or VP".

For the purposes of this paper, we assume that for the matrix part of the sentence $b u$ and $m$ are in the Spec of a functional projection in the extended projection of VP, like, for instance, ModP, and that it is proclitic to whatever material is in the head of this projection; see (26).

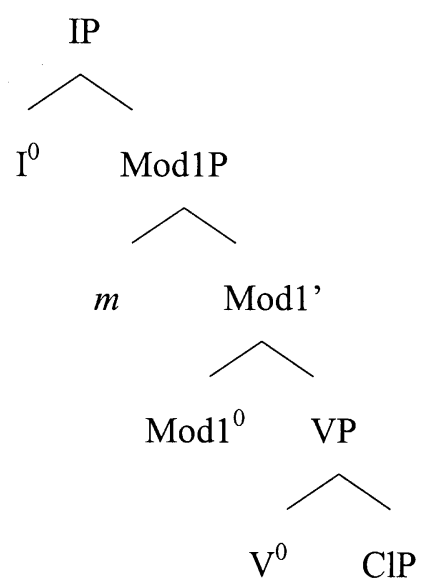

Turning now to the $d a k$-sentences, let us look at permission-dak in the matrix $\operatorname{Mod} 1^{0}$ first. The derivation of a sentence like (5a) (the negative counterpart of (1a); repeated here) is unproblematic and we won't spell it out.

(5) a. keoi m-zaa-dak li-ga ce

3s NEG-drive-DAK this-CL car

's/he cannot drive this car' - permission reading only

As to negative potential-dak sentences, like (6a), the negative counterpart of (1b) (given here once more), we need to address two questions.

(6) a. keoi lo-m-hei li-seung syu 3s take-NEG-up this-box book

's/he cannot lift this box of books' - potential reading only

First, why can the matrix negation, i.e., the negative element in the Spec of a matrix FP, not serve as the negation for the potential? In other words, why is (27) not grammatical? 


\section{(27) *keoi m-lo-dak-hei li-seung syu \\ 3s NEG-take-DAK-up this-box book}

Secondly, why is potential dak replaced by $m$ 'not'?

As to the second question, why $m$ replaces dak in the potential rather than cooccurring with it, we don't really have an answer (see also footnote 4). We would like to refer back to the suggestion by Wang (1980) that the negative potential predates the positive one. This has the consequence, that $\mathrm{V}-m-\mathrm{R}$ is not the negative form of $\mathrm{V}-d a k-\mathrm{R}$, but that $\mathrm{V}-d a k-\mathrm{R}$ is the positive form of $\mathrm{V}-m-\mathrm{R}$. It may be the case that $m$ occupies the same position as dak, the head of Mod2P. $M$ would in these cases perhaps be a negative verb, a category that is not unknown in Chinese, as we saw in the beginning of this section on negation; aside from the verbs meaning 'not have', there are more such verbs. Mandarin, to give just one example, has beng 'need not'.

We now turn to the first question just raised: Why couldn't the negation element in the matrix clause serve as the negation for the potential? The answer is by now familiar: once the verb is caught up with $d a k$ (or, for that matter, any other material in the small clause), it cannot raise. As the following sentence shows, it is very well possible to have a negation element in the matrix sentence and a potential dak in one sentence, as long as some other element occupies a position such that $m$ can cliticize to it.

$$
\begin{aligned}
& \text { keoi m holang sik-dak-saai wun-faan } \\
& \text { 3sg NEG possible eat-DAK-entire bowl-rice } \\
& \text { 'it cannot be that } \mathrm{s} / \mathrm{he} \text { is able to finish that bowl of rice' }
\end{aligned}
$$

\subsection{Why not two DAKs in one sentence?}

We never find two daks in one sentence, not even in sentences with a result phrase. The explanation runs along by now familiar lines: if there is a dak in Mod2 ${ }^{0}$, the verb will phonologically merge with it, and would not be able to raise to $\operatorname{Mod} 1^{0}$ as a result of which the structure will crash.

\subsection{Conclusion}

The basics of our account of the facts in Section 2 can be summarized as follows. If probe and goal are adjacent, Agree takes effect and is followed by phonological merger. If probe and goal are not adjacent, the goal raises to a position adjacent to the probe.

In (29) we give an overview of when we have what.

(29) a. RAISING

1. $\mathrm{V}^{0}$ to dak in $\operatorname{Mod} 1^{0}$

2. SC predicate head (R) to $\mathrm{Asp}^{0}$ in the $\mathrm{SC}$ 
b. AdJACENCY From THE START

1. $\mathrm{V}^{0}$ and dak in Mod2

2. $\mathrm{V}^{0}$ and material in $\mathrm{Asp}^{0}$ (e.g. zo)

As to (29a1), $\mathrm{V}^{0}$ raises to $d a k$ in $\operatorname{Mod} 1^{0}$ because $d a k$ itself is not capable of checking the verbal features with the head of the projection immediately dominating Mod1P, a projection we assumed is IP. Movement to $\mathrm{Mod}^{0}$ brings $\mathrm{V}^{0}$ in a position adjacent to $\mathrm{I}^{0}$. For (29a2), R moves to check features in AspP and to check features, under adjacency, with $\mathrm{V}^{0}$ which are related to the establishment of an interpretative T-chain between the predicates in the sentence. The cases in (29b) need no further explanation.

After feature checking by Agree under adjacency, phonological merger takes place. The consequence of this operation is that no element can be excorporated out of the ensuing whole; verbs caught up in a merger cannot move out to check features, for instance. The result of a merger is immobile, though it can check features by adjacency.

We find interesting confirmation of some of these claims when we look at another Sinitic language, Hakka.

\section{Hailu Hakka ${ }^{20}$}

Hailu Hakka's cognate of dak is tet. Like dak, tet is a bound morpheme and it cannot check features with $\mathrm{I}^{0}$ when $\mathrm{I}^{0}$ is empty. On the other hand, tet differs from dak in several respects. First of all, tet has several root modal meanings, not primarily permission as in Cantonese; among the other readings is ability ${ }^{21}$ Secondly, Hailu Hakka has no positive potential V-tet-R sentences; only negative potential sentences are formed productively: ${ }^{22}$
a. ki zhi-m-si kai'er
3sg kill-NEG-dead chicken
's/he can't (manage to) kill the chicken'
b. *ki zhi-tet-si kai'er
3sg kill-DAK-dead chicken

Finally, and most interestingly, in the context of matrix-tet, Hailu Hakka does not have verb raising. Instead, it features $d o$-support.

\footnotetext{
${ }^{20}$ The variety of Hakka we discuss here is Hailu Hakka, spoken in Taiwan. We thank Hsieh Feng-fan for making us aware of the relevance of Hakka (and for providing the data).

${ }^{21}$ Hailu Hakka lacks cognates of other modals expressing ability, like Mandarin neng and Cantonese hoji. For acquired ability it uses hiau 'know'; cf. (2a) above.

22 Mandarin reveals a similar tendency: negative potentials are much less restricted than positive ones (Liu, 1989; Cheng and Sybesma, 2003).
} 
(31)
a. ngai co-tet shit niot
1 sg do-DAK eat meat
'I can eat meat' (both permission and ability)
$\begin{array}{ccc}\text { b. *ngai } & \text { shit-tet niot } \\ 1 \text { sg } & \text { eat-DAK } & \text { meat }\end{array}$

It also has sentences like the following, which is used as the positive counterpart of (30b), at least in one of the two meanings it has - it has both a permission and an ability reading.
ki co-tet zhi-si kai'er
3sg do-DAK kill-dead chicken
's/he can kill the chicken'

These facts can be interpreted to support our analysis in the following way. We have argued that a projection is dominating the projection headed by DAK. We labeled it IP, but it could be something else. However, it plays a very central role, very much like (any sub-projection of) IP in the sense that, as we argued, the head of this projection has to check features with the highest verbal element, so let's stick to this label. In Cantonese (and Hailu Hakka), DAK cannot do this, as a result of which the main verb raises to the position occupied by DAK. If the main verb cannot raise (for instance, when it has undergone phonological merger with material in its complement), the derivation crashes.

For reasons we don't understand, Hailu Hakka has no verb raising even in cases where the verb is not caught up with material in its complement; it resorts to dosupport. Since it has this option, it also uses it in other cases, cases like (32), for instance, in which the verb zhi 'kill' has been immobilized by phonological merger with the head of the resultative small clause, $s i$ 'dead'.

Interestingly, that $c o$ 'do' is inserted into $\mathrm{I}^{0}$, and not into the same position as tet, is shown by the negative counterparts of $d o$-support sentences like (31a) and $(32) \cdot{ }^{23}$
a. ngai co-m-tet shit niot (cf. (31a))
1 sg do-NEG-DAK eat meat
'I cannot eat meat'
b. ki co-m-tet zhi-si kai'er (cf. (32))
3sg do-NEG-DAK kill-dead chicken
'he cannot kill the chicken'

Co 'do' is inserted in a position above the negation. In view of the structure in (26), this can only be $\mathrm{I}^{0}$.

\footnotetext{
${ }^{23}$ The sentence in (30a) is another negative counterpart of (32), and is, of course, exclusively potential.
} 


\section{Conclusions}

In this paper we have presented an analysis of sentences with a modal element in post-verbal position in Cantonese and Hailu Hakka.

As to this modal element, DAK, we conclude that there are two positions in which it can be inserted: in the matrix clause and in the resultative small clause. In the former, DAK denotes root modal meanings like permission and ability. In the latter position, it exclusively has the potential meaning. Furthermore, in Cantonese and Hakka, DAK is a defective verb: it is a bound morpheme and it cannot check the features in $\mathrm{I}^{0}$ by itself. This has consequences for the derivation of the sentences containing dak, as was accounted for in detail in this paper.

The analysis, if correct, may have a number of interesting consequences, beyond the topic of the postverbal modal element. For Chinese linguistics, the evidence for the presence of a functional head which may be identifiable as $\mathrm{I}^{0}$ is an important discovery. It has always been a question whether Chinese languages feature a functional element like $\mathrm{I}^{0}$ playing a crucial role in the licensing of the verb. If there were theoretical reasons to adopt such a head, there never was any evidence for it. Now, we may have found some. Presumably, finite $\mathrm{I}^{0}$ is always empty in Chinese and in sentences without matrix-DAK in languages in which it is defective as in Cantonese and Hakka, feature checking is done through adjacency. ${ }^{24}$

For syntactic theory more generally, we developed the idea that Agree only takes effect under adjacency and that in cases of non-adjacency, the goal moves towards the probe so as to get adjacent to it. Agree, we also suggested, is typically followed by phonological merger, possibly an instance of phasal spell out, which has the consequence of making inaccessible anything that is caught up in the merger.

\section{References}

Abney, S., 1986. The English noun phrase in its sentential aspect. Doctoral Dissertation, MIT. Bobaljik, J.D., 1995. Morphosyntax: the syntax of verbal inflection. Doctoral Dissertation, MIT.

Cheng, L., Sybesma, R., 1998. On dummy objects and the transitivity of run. In: van Bezooijen, R.,

Kager, R. (Eds.), Linguistics in the Netherlands 1998. John Benjamins, Amsterdam, pp. 81-93.

Cheng, L., Sybesma, R., 1999. Bare and not-so-bare nouns and the structure of NP. Linguistic Inquiry 30 (4), 509-542.

Cheng, L., Sybesma, R., 1999. Forked modality. In: Cornips, L., Fikkert, P. (Eds.), Linguistics in the Netherlands 2003. John Benjamins, Amsterdam.

Cheung, S., 1972. Xianggang yueyu yufa yanjiu (Explorations of the Grammar of Hongkong Cantonese. Chinese University of Hongkong).

\footnotetext{
24 Interestingly, as in English according to Bobaljik (1995), adjuncts don't interfere in calculating adjacency. In the following Mandarin sentence, the checking of the I-V features is done through adjacency, despite the presence of an adjunct.

(i) wo zai jia-li xie xin

$1 \mathrm{sg}$ at home-inside write letter

'I was writing a letter at home'
} 
Chomsky, N., 2000. Minimalist inquiries: The framework. In: Martin, R., Michaels, D., Uriagereka, J. (Eds.), Step by step. Essays in Minimalist Syntax in Honor of Howard Lasnik. MIT Press, Cambridge, Mass, pp. 89-155.

Chomsky, N., 2001. Derivation by phase. In: Kenstowics, M. (Ed.), Ken Hale. A Life in Language. MIT Press, Cambridge, MA, pp. 1-52.

Enfield, N., 2002. Linguistic Epidemiology. Semantics and Grammar of Language Contact in Mainland Southeast Asia. Routledge, London.

Ernst, T., 1995. Negation in Mandarin Chinese. Natural Language and Linguistic Theory 13 (4), 665-707.

Guéron, J., Hoekstra, T., 1989. T-chains and the constituent structure of auxiliaries. Annali di Ca' Foscari (special issue: A. Cardinaletti, G. Cinque and G. Giusti (Eds.) Constituent Structure), 35-100.

Guéron, J., Hoekstra, T., 1990. Chaînes temporelles et phrases réduites. In: Obenauer, H.-G., Zribi-Hertz, A. (Eds.), Structure de la Phrase a Théorie du Liage. Presses Universitaires de Vincennes, pp. 69-91.

Guéron, J., Hoekstra, T., 1995. The temporal interpretation of predication. In: Cardinaletti, A., Guasti, M.T. (Eds.), Small Clauses (Syntax and Semantics 28). Academic Press, New York, pp. 77-108.

Harley, H., Noyer, R., 2003. Distributed morphology. In: Cheng, L., Sybesma, R. (Eds.), The Second Glot International State-of-the-Article Book. Mouton de Gruyter, Berlin, pp. 463-496.

Hoekstra, T., 1988. Small clause results. Lingua 74, 101-139.

Hoekstra, T., 1992. Subjects inside out. Revue Québécoise de Linguistique 22 (1), 45-75.

Huang, C.T.J., 1988. Wo pao de kuai and Chinese phrase structure. Language 64, 274-311.

Killingley, S.-Y., 1993. Cantonese (Languages of the World/Materials 06). Lincom Europa, München.

Koopman, H., Szabolsci, A., 2000. Verbal Complexes. MIT Press, Cambridge, MA.

Kwok, H., 1971. A Linguistic Study of the Cantonese Verb. University of Hong Kong.

Li, X., 1996. Deriving distributivity in Mandarin Chinese. Doctoral Dissertation, UC Irvine.

Liu, Y., 1989. Keneng buyu yongfa de yanjiu (Explorations of the use of the potential complement construction). Hanyu yufa lunji (Collection of Papers on Chinese Grammar). Xiandai, Peking, pp. 129.

Lu, J.G., 1999. Yueyu “de”-zi de yongfa (The use of DAK in Cantonese). Fangyan, 215-220.

Matthews, S., Yip, V., 1994. Cantonese. A Comprehensive Grammar. Routledge, London.

Nancarrow, O., Luke, K.-K., 1998. Auxiliary verbs in Cantonese. In: Matthews, S. (Ed.), Studies in Cantonese Linguistics, Linguistic Society of Hong Kong, pp. 81-100.

Ota, T., 1958. Zhongguoyu lishi wenfa (Historical Grammar of the Chinese language) (Chinese translation 1987, Jiang, S.Y. and Xu, C.H. Beijing Daxue Chubanshe, Peking).

Peng, X.C., 1998. Guangzhouhua de "V-DAK-(O)" jiegou (The V-DAK-(O) construction in the Guangzhou dialect). Fangyan 53-57.

Peyraube, A., 1996. Recent issues in Chinese historical syntax. In: Huang, C.-T.J., Li, Y.-H.A. (Eds.), New Horizons in Chinese Linguistics. Kluwer, Dordrecht, pp. 161-213.

Simpson, A., 2001. Focus, presupposition and light predicate raising in East and Southeast Asia. Journal of East Asian Linguistics 10 (2), 89-128.

Sun, C., 1996. Word-order Change and Grammaticalization in the History of Chinese. Stanford University Press.

Svenonius, P., 1994. Dependent nexus. Doctoral Dissertation, UCSC.

Sybesma, R., 1999. The Mandarin VP. Kluwer, Dordrecht.

Sybesma, R., Vanden Wyngaerd, G., 1997. Realizing end points: the syntax and semantics of Dutch ge and Mandarin le. In: Coerts, J., de Hoop, H. (Eds.), Linguistics in the Netherlands 1997. John Benjamins, Amsterdam.

Tang, S.-W., 2002. Focus and dak in Cantonese. Journal of Chinese Linguistics 30 (2), 266-309.

Uriagereka, J., 1999. Multiple spell-out. In: Epstein, S.D., Hornstein, N. (Eds.), Working Minimalism. MIT Press, Cambridge, MA, pp. 251-282.

Wang, L., 1980. Hanyu shi gao (Outline of the History of Chinese). Zhonghua Shuju, Peking.

Wong, C., 1998. First auxiliaries and modality in child Cantonese. In: Matthews, S. (Ed.), Studies in Cantonese Linguistics. Linguistic Society of Hong Kong, Hong Kong, pp. 113-132.

$\mathrm{Wu}$, Y.J., 2001. The development of $[\mathrm{DE}+\mathrm{V}]$ and $[\mathrm{V}+\mathrm{DE}]$ constructions in the Hunan dialects. Yuyan Yanjiu 45-59. 
Yang, P., 1989. "dongci + de + binyu" jiegou de chansheng he fazhan (Origin and development of the "verb + de + object" construction). Zhongguo Yuwen 2, 126-136.

Yang, B., He, L., 1992. gu Hanyu yufa ji qi fazhan (Old Chinese Grammar and its Development). Yuwen, Peking.

Yip, M., 1988. Negation in Cantonese as a lexical rule. Bulletin of the Institute of History and Philology LIX-2, 449-477.

Zao, G., 1995. jindai Hanyu zhuci (Function Words in Pre-modern Mandarin). Yuwen, Peking. 